OPEN ACCESS

Edited by:

Erol Yilmaz,

Recep Tayyip Erdoğan University,

Turkey

Reviewed by:

Jiangyu Wu,

China University of Mining and

Technology, China

Chongchong Qi,

Central South University, China

*Correspondence:

Baomeng Chang changbaomeng@163.com

Cuifeng Du

1367724455@qq.com

Specialty section:

This article was submitted to

Structural Materials,

a section of the journal

Frontiers in Materials

Received: 25 August 2021 Accepted: 23 September 2021 Published: 02 November 2021

Citation:

Chang B, Du C, Chu X and Zhang L (2021) Study on the Optimization of

Filling Ratio and Strength Variation Characteristics of Cemented Backfills

Containing Fly Ash.

Front. Mater. 8:764410.

doi: $10.3389 /$ fmats.2021.764410

\section{Study on the Optimization of Filling Ratio and Strength Variation Characteristics of Cemented Backfills Containing Fly Ash}

\author{
Baomeng Chang ${ }^{1,2 *}$, Cuifeng $\mathrm{Du}^{1,2 *}$, Xiaofeng $\mathrm{Ch}^{3}$ and Long Zhang ${ }^{3}$ \\ ${ }^{1}$ School of Civil and Resources Engineering, University of Science and Technology Beijing, Beijing, China, ${ }^{2}$ State Key Laboratory \\ of High-Efficient Mining and Safety of Metal Mines of Ministry of Education, University of Science and Technology Beijing, Beijing, \\ China, ${ }^{3}$ Jiaojia Gold Mine, Shandong Gold Mining (Laizhou) Co., Ltd., Yantai, China
}

The fly ash for underground filling can effectively utilize solid waste, improve the strength of the backfill, and reduce the cost, thus creating good social and economic benefits. Relying on the filling requirements of a gold mine in Jilin, this paper carried out the filling ratio experiments containing fly ash and analyzed the reasons for the variation of the backfill strength based on the hydration characteristics of cement and fly ash and scanning electron microscope. The results show that fly ash has an overall effect on the strength of the backfill, and the strength development is mainly concentrated in the period of 28-56 d; when the filling slurry contains tailings, the excessive amount of fly ash is likely to cause a large number of fine particles to obstruct the hydration of cementitious materials; when the concentration of the filling slurry is $74 \%$, the cement content is $5 \%$, the mass ratio of waste rock-tailings-fly ash is $6: 2: 3$, and the $\mathrm{CaO}$ content is 6:3, the strength of the backfill is significantly higher than the current strength of the backfill of the mine, and the cost can be saved by RMB 0.56 per cubic meter; the strength characteristics of the backfill mainly depend on the pore structure; when the filling slurry is better matched, the cement and fly ash hydration generates a large number of C-S-H gel particles, which wraps the aggregate to form a dense structure with less pore structure, and the strength of the backfill increases; the strength variation process of backfill containing cement and fly ash is divided into cement hydration period, fly ash infiltration period, and slurry hardening period. To enhance the strength of the backfill, it is necessary to determine the appropriate cementitious material ratio to maximize the excitation of fly ash hydration during the fly ash infiltration period, and the hydration produces a gel structure with an excellent aggregate ratio. In addition, the slurry hardening reduces the porosity of the backfill. The results can provide basic data and theoretical guidance for further promotion and application of fly ash in mine filling.

Keywords: fly ash, cementitious filling, hydration, filling ratio, scanning electron microscope

\section{INTRODUCTION}

The cemented filling method is increasingly used in metal mines because of its effective ground pressure control, as well as its good environmental and economic benefits (Chen et al., 2021; Li et al., 2021). However, as mineral resources enter the deep mining stage, the ground pressure control and filling costs are increasing. There is an urgent need to find low-cost alternative cementitious materials that can increase the strength of the backfill (Yin et al., 2018; Qi and Fourie, 2019). 
Fly ash is a powdered solid waste discharged from coal-fired thermal power plants after burning pulverized coal, whose reserves are huge and inexpensive (Nath and Sarker, 2015; Fang et al., 2018; Fu et al., 2018; Fan et al., 2019). As a substitute for filling cementing material, fly ash can reduce the cost of filling, improve the strength of the backfill, and create good economic and social benefits (Azmee and Shafiq, 2019; Ardahanli et al., 2021; Zafar and Alqahtani, 2021). Some scholars have studied the application of fly ash in the field of mine filling (Capasso et al., 2019; Chen et al., 2020; Yang, 2020): Behera et al. analyzed the chemical composition, morphology, and mineral composition of fly ash to explore its application prospects in mine filling (Behera et al., 2019); Liang et al. optimized the best filling ratio of fly ash, quicklime, gypsum, and cement by orthogonal experiments (Liang et al., 2019); Wang et al. used fly ash as cementitious material and coal gangue as aggregate to determine the best ratio of filling slurry by integrated equilibrium method (Wang et al., 2019); Yang et al. predicted the effect of fly ash content on backfill strength based on backfill strength and BP neural network model (Yang et al., 2019); Wang studied the properties of compressive strength of fly ash-doped filling slurry (Wang, 2020); Liu et al. analyzed the effect of different excitants on the strength properties of fly ash-containing backfill (Liu et al., 2021); Cui et al. studied the effect of excitants on the strength of fly ash-containing backfill by controlling variables and mechanical analysis (Cui et al., 2018). Current research on backfill containing fly ash has focused more on macroscopic strength variation, while research on the influence of microstructure on the strength of backfill and the determination of the stages of strength variation of backfill needs to be further developed. Therefore, based on the filling demand of a gold mine in Jilin and from the perspectives of macroscopic strength and microstructural changes, this paper carried out experiments of fly ash on the effect of backfill strength and the optimization of the filling ratio containing fly ash, analyzed the effect of fly ash on the strength of the backfill, selected the optimal filling ratio for the mine, and determined the causes of the strength variation, the strength variation stage, and the influence of each stage on the strength development of the backfill containing fly ash based on the hydration characteristics of cement and fly ash and the scanning electron microscope. The research provides basic data and theoretical guidance for the further promotion and application of fly ash in mine filling.

\section{ENGINEERING BACKGROUND}

The gold mine in Jilin adopts the sublevel open stopping with delayed filling, which is divided into two phases according to the sequence of mining. The first phase of the stope after filling needs to support the surrounding rock to ensure the safety of the second phase of mining. For the mining requirement, the $28 \mathrm{~d}$ strength of the backfill of the first phase stope should reach $0.8 \mathrm{MPa}$. The filling aggregate is tailings and crushed waste rock, cement is used as cementing material, and the slurry concentration reaches $70-75 \%$, which is transported to the stope by gravity. However, since the mine's tailings contain cyanide, it cannot

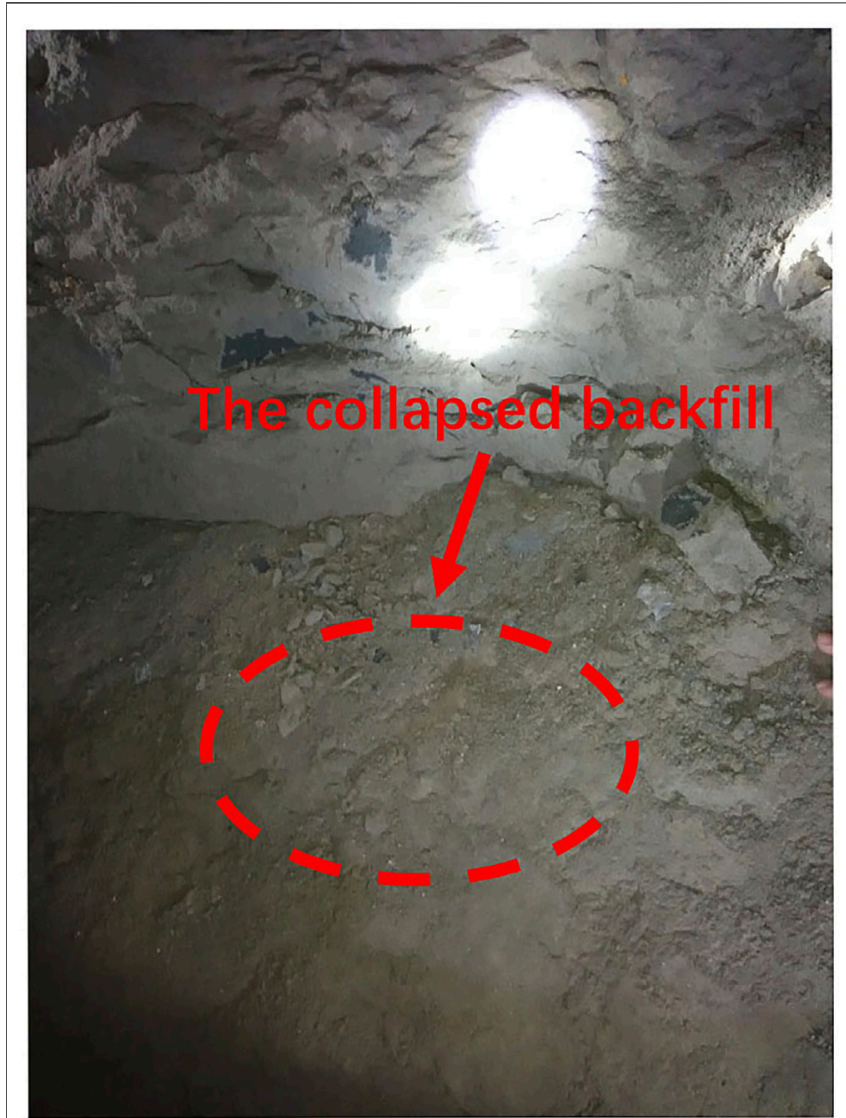

FIGURE 1 | The collapsed backfill of the stope.

be used for underground filling. Therefore, all the filling tailings are purchased. Moreover, the filling times line is increasing with the mining, so the slurry concentration needs to be reduced to achieve gravity transportation. To achieve the expected backfill strength, it is necessary to increase the cement consumption, which further increases the filling cost. According to monitoring the existing backfill quality of the mine, the backfill strength can only reach $0.67 \mathrm{MPa}$ at $28 \mathrm{~d}$ and $1.05 \mathrm{MPa}$ at $56 \mathrm{~d}$ when the cement content is $10 \%$ and the waste rock-tailings ratio is $3: 1$. The insufficient backfill strength has led to many collapses (Figure 1 shows the collapsed backfill of the stope), which seriously threatens the second phase of the stope. Based on this background, it is proposed to add fly ash to the filling material of the mine and carry out proportional experiments of cemented filling with fly ash to increase the strength of the backfill and reduce the filling cost.

\section{EXPERIMENT MATERIALS AND SCHEME}

\section{Experiment Materials}

1) The moisture content of the waste rock used for filling is $3.63 \%$, and the gradation is measured by manual screening, as shown in Figure 2. The particle size of the waste rock ranges 

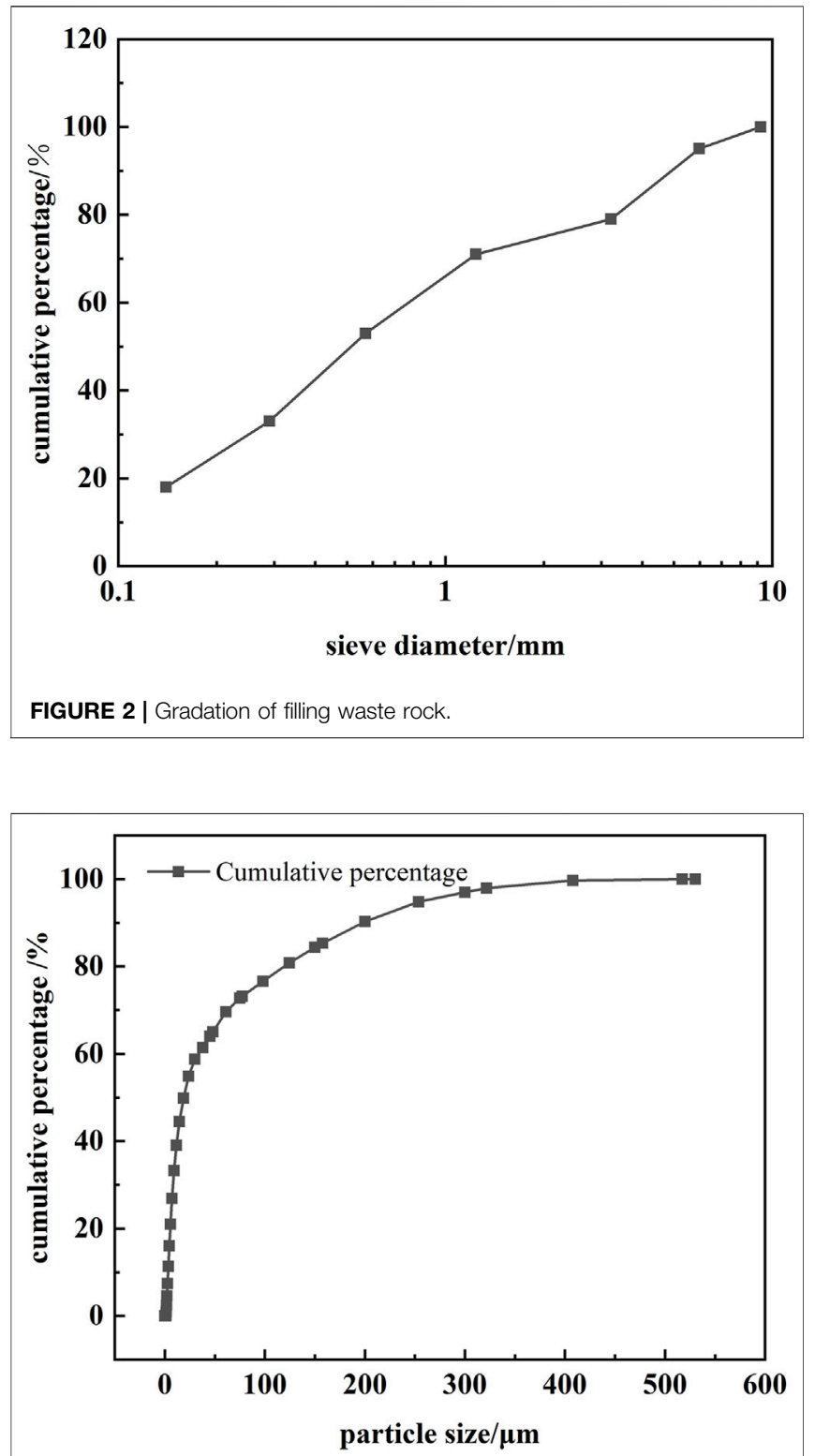

FIGURE 3 | Cumulative percentage of tailings particle size.

from 0.1 to $10 \mathrm{~mm}$, and the range of $-2 \mathrm{~mm}$ is relatively high, nearly $70 \%$.

2) The moisture content of tailings is $12.36 \%$. Particle size distribution is tested by the laser particle size analyzer, and the result is shown in Figure 3. The particle size distribution range is $0.243-521.6 \mu \mathrm{m}$, of which $0 \sim 1 \mu \mathrm{m}$ accounted for $1.45 \%, 1-10 \mu \mathrm{m}$ accounted for $14.21 \%, 10-100 \mu \mathrm{m}$ accounted for $57.34 \%$, and $100-530 \mu \mathrm{m}$ accounted for $27 \%$. The mineral composition of tailings tested by XRD is shown in Figure 4 and is mainly quartz, albite, and dolomite, and the main chemical composition tested by $\mathrm{XRF}$ is $\mathrm{SiO}_{2}$ and $\mathrm{Al}_{2} \mathrm{O}_{3}$, accounting for $83.51 \%$.

3) The cement is 32.5 ordinary Portland cement, the main mineral composition and chemical composition of which

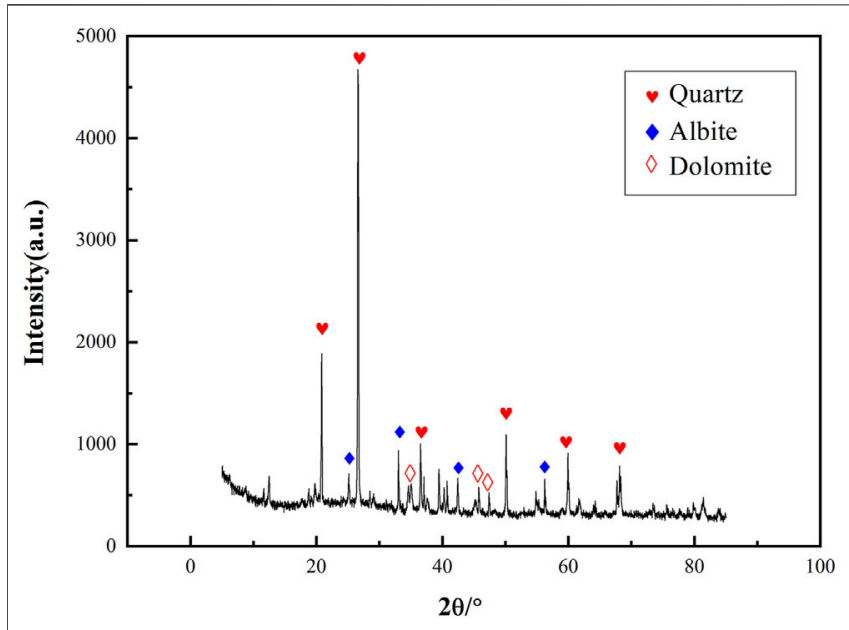

FIGURE 4 | Mineral composition of tailings.

TABLE 1 | Chemical composition of cement.

\begin{tabular}{lccccc} 
Chemical composition & $\mathbf{C a O}$ & $\mathbf{S i O}_{\mathbf{2}}$ & $\mathbf{A l}_{\mathbf{2}} \mathbf{O}_{\mathbf{3}}$ & $\mathbf{F e}_{\mathbf{2}} \mathbf{O}_{\mathbf{3}}$ & $\mathbf{M g O}$ \\
\hline Content/\% & 52.89 & 27.72 & 7.56 & 2.89 & 3.86 \\
Chemical composition & $\mathrm{Na}_{2} \mathrm{O}$ & $\mathrm{K}_{2} \mathrm{O}$ & $\mathrm{P}_{2} \mathrm{O}_{5}$ & $\mathrm{MnO}$ & $\mathrm{TiO}_{2}$ \\
Content/\% & 0.79 & 1.34 & 0.27 & 1.87 & 0.81
\end{tabular}

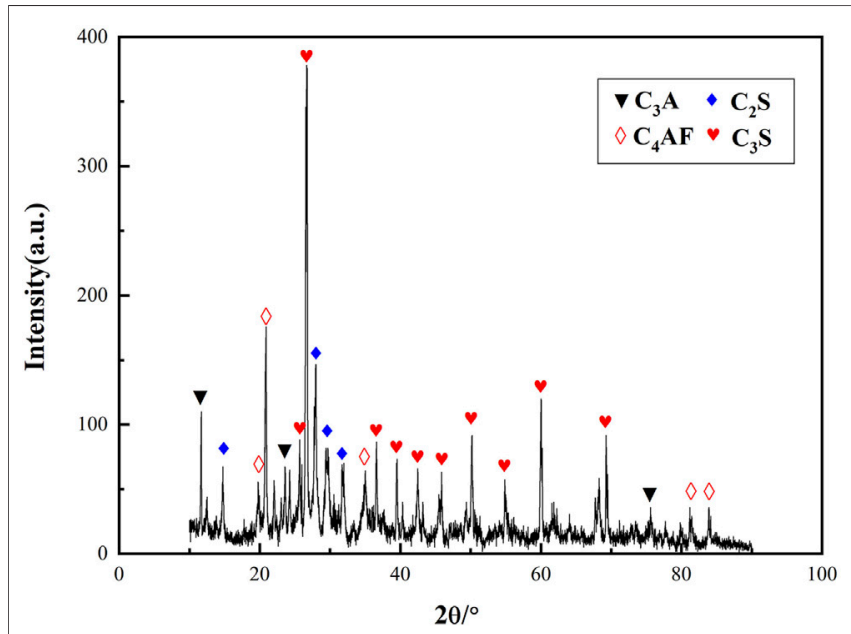

FIGURE 5 | Mineral composition of cement.

were determined by XRD and XRF, respectively. The chemical composition is shown in Table $\mathbf{1}$, and the mineral composition is shown in Figure 5. The main chemical composition of the cement is $\mathrm{CaO}$ and $\mathrm{SiO}_{2}$, accounting for $80.61 \%$ of the total cement. The main mineral composition is tricalcium silicate $\left(3 \mathrm{CaO} \bullet \mathrm{SiO}_{2}\right.$, abbreviated as $\left.\mathrm{C}_{3} \mathrm{~S}\right)$, dicalcium silicate $\left(2 \mathrm{CaO} \bullet \mathrm{SiO}_{2}\right.$, abbreviated as $\left.\mathrm{C}_{2} \mathrm{~S}\right)$, tricalcium aluminate $\left(3 \mathrm{CaO} \bullet \mathrm{Al}_{2} \mathrm{O}_{3}\right.$, abbreviated as $\mathrm{C}_{3} \mathrm{~A}$ ), and tetra-calcium ferroaluminate 


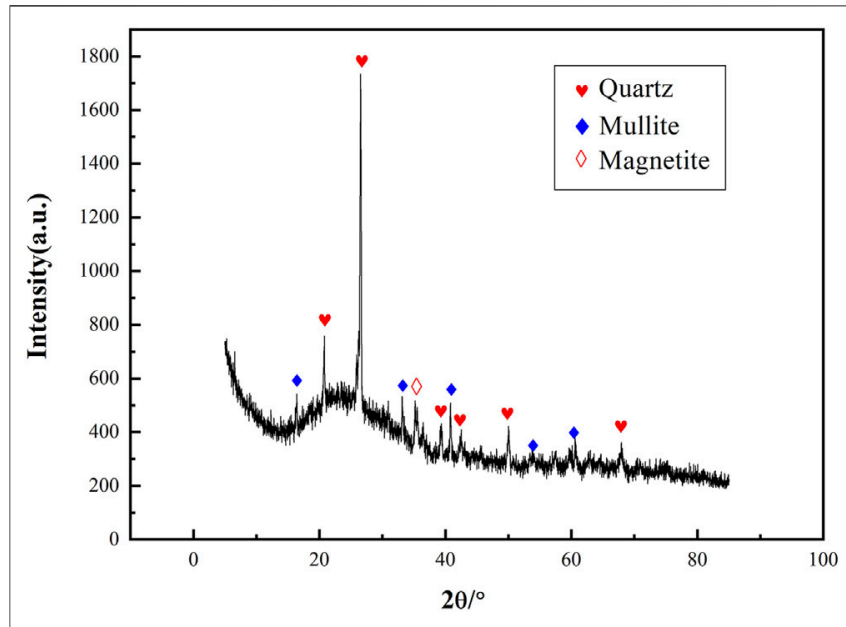

FIGURE 6 | Mineral composition of fly ash.

$\left(4 \mathrm{CaO} \bullet \mathrm{Al}_{2} \mathrm{O}_{3} \bullet \mathrm{Fe}_{2} \mathrm{O}_{3}\right.$, abbreviated $\mathrm{C}_{4} \mathrm{AF}$ ), with contents of $49.18,16.08,8.56$, and $7.02 \%$, respectively.

4) The moisture content of fly ash is $8.69 \%$ and the chemical composition is $\mathrm{SiO}_{2}$ content $54.1 \%, \mathrm{Al}_{2} \mathrm{O}_{3}$ content $23.2 \%$, $\mathrm{Fe}_{2} \mathrm{O}_{3}$ content $4.3 \%$, and $\mathrm{CaO}$ content $2.9 \%$. The mineral composition is shown in Figure $\mathbf{6}$ and is mainly quartz, mullite, and magnetite. According to ASTM C 618 standard, the fly ash has low $\mathrm{CaO}$ content and poor activity, and it belongs to class F (Dai et al., 2021).

\section{Experiment Scheme}

It was determined in the field that the filling slurry concentration realizes gravity transportation at about $74 \%$, when the slurry diffusivity was more than $80 \mathrm{~cm}$, with good workability and no segregation and precipitation (Xiao et al., 2019; Huang et al., 2021). Therefore, this value was taken as the standard of filling slurry concentration. According to the filling materials in the mine, experiments of fly ash on the effect of the backfill strength and the optimization of the backfill ratio were carried out. The experiment scheme of fly ash on the effect of the backfill strength is shown in Table 2, and the optimization experiments of the backfill ratio are carried out based on the results of the experiments in Table 2.

The materials of each experiment scheme placed in the mixing bucket were weighted. The mixer was used to mix the slurry evenly. Then, the slurry was loaded into the mold of $\varphi 80 \times 200 \mathrm{~mm}$. Because of the low initial strength of the backfill, it was easy to be damaged after demoulding. Therefore, it was demoulded after $24 \mathrm{~h}$ and moved to the constant temperature and humidity box for maintenance, with the temperature set at $20 \pm 1^{\circ} \mathrm{C}$ and humidity at $95 \%$. After curing to the predetermined age, the uniaxial compressive strength was measured by WES-100 hydraulic universal testing machine, and representative backfill blocks were selected and made into standard specimens. The microstructure characteristics were observed by scanning electron microscope after gold spraying (Hu et al., 2019; Xie, et al., 2020) to analyze the variation mechanism of backfill strength. The flow chart of experiments is shown in Figure 7.

\section{ANALYSIS OF EXPERIMENT RESULTS Study on the Effect of Fly Ash on the Strength of Backfill}

To analyze the effect of fly ash on the strength of backfill, group A and group B experiments were conducted, respectively. The results of 28,56, and $90 \mathrm{~d}$ uniaxial compressive strength of backfill are shown in Figure 8.

When the cement content was $9 \%$, the $28 \mathrm{~d}$ uniaxial compressive strength of the backfill without fly ash was $0.57 \mathrm{MPa}$ and the $56 \mathrm{~d}$ uniaxial compressive strength was $0.97 \mathrm{MPa}$. As can be seen from Figure 8, the strength of the backfill in both groups A and B is significantly improved under the condition of adding fly ash. The $28 \mathrm{~d}$ uniaxial compressive strength is greater than $1.65 \mathrm{MPa}$. The $56 \mathrm{~d}$ uniaxial compressive strength is greater than $2.24 \mathrm{MPa}$. That is, the addition of fly ash in the slurry has an overall promoting effect on the strength of the backfill.

As shown in Figure 8A, when the filling aggregate was all waste rock, the strength of the backfill gradually increased with the increase of fly ash to cement mass ratio, and both of them increased approximately linearly. The $56 \mathrm{~d}$ strength was 2.24 times the $28 \mathrm{~d}$ strength (mean value), while the strength grew less from 56 to $90 \mathrm{~d}$ during the maintenance period. The strength development of backfill containing fly ash was mainly concentrated in the maintenance period from 28 to

TABLE 2 | Experiments of the fly ash on the effect of backfill strength.

\begin{tabular}{|c|c|c|c|c|}
\hline Number & Concentration/\% & Cement content $/ \%$ & $\begin{array}{l}\text { The mass ratio } \\
\text { of fly ash-cement }\end{array}$ & $\begin{array}{c}\text { The mass ratio } \\
\text { of waste rock-tailings }\end{array}$ \\
\hline$A-1$ & 74 & 9 & 2 & All waste rock \\
\hline$A-2$ & 74 & 9 & 3 & All waste rock \\
\hline$A-3$ & 74 & 9 & 4 & All waste rock \\
\hline$A-4$ & 74 & 9 & 5 & All waste rock \\
\hline B-1 & 74 & 9 & 2 & $3: 1$ \\
\hline B-2 & 74 & 9 & 3 & $3: 1$ \\
\hline B-3 & 74 & 9 & 4 & $3: 1$ \\
\hline B-4 & 74 & 9 & 5 & $3: 1$ \\
\hline
\end{tabular}




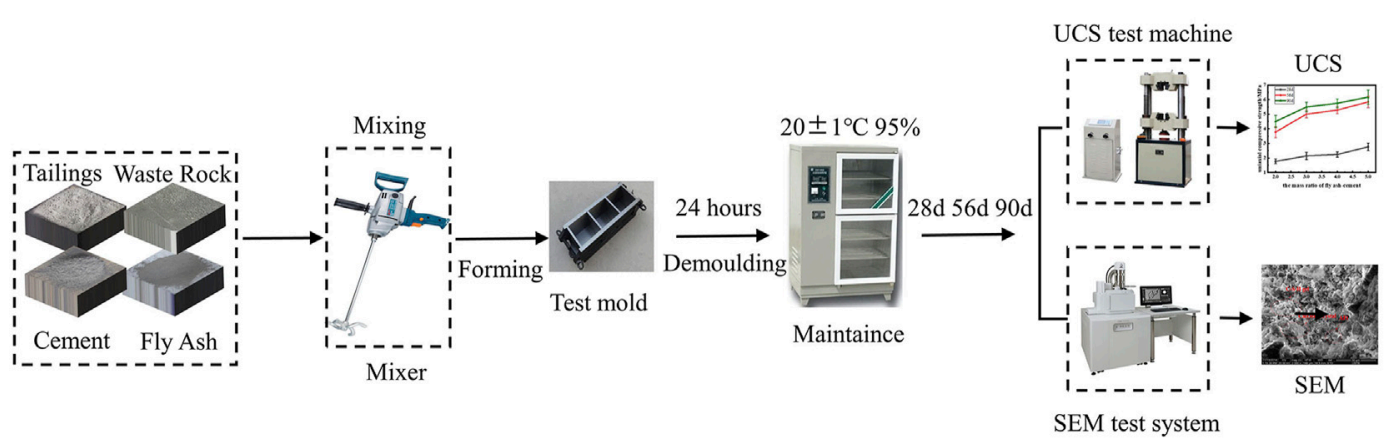

FIGURE 7 | Experiments flow chart.

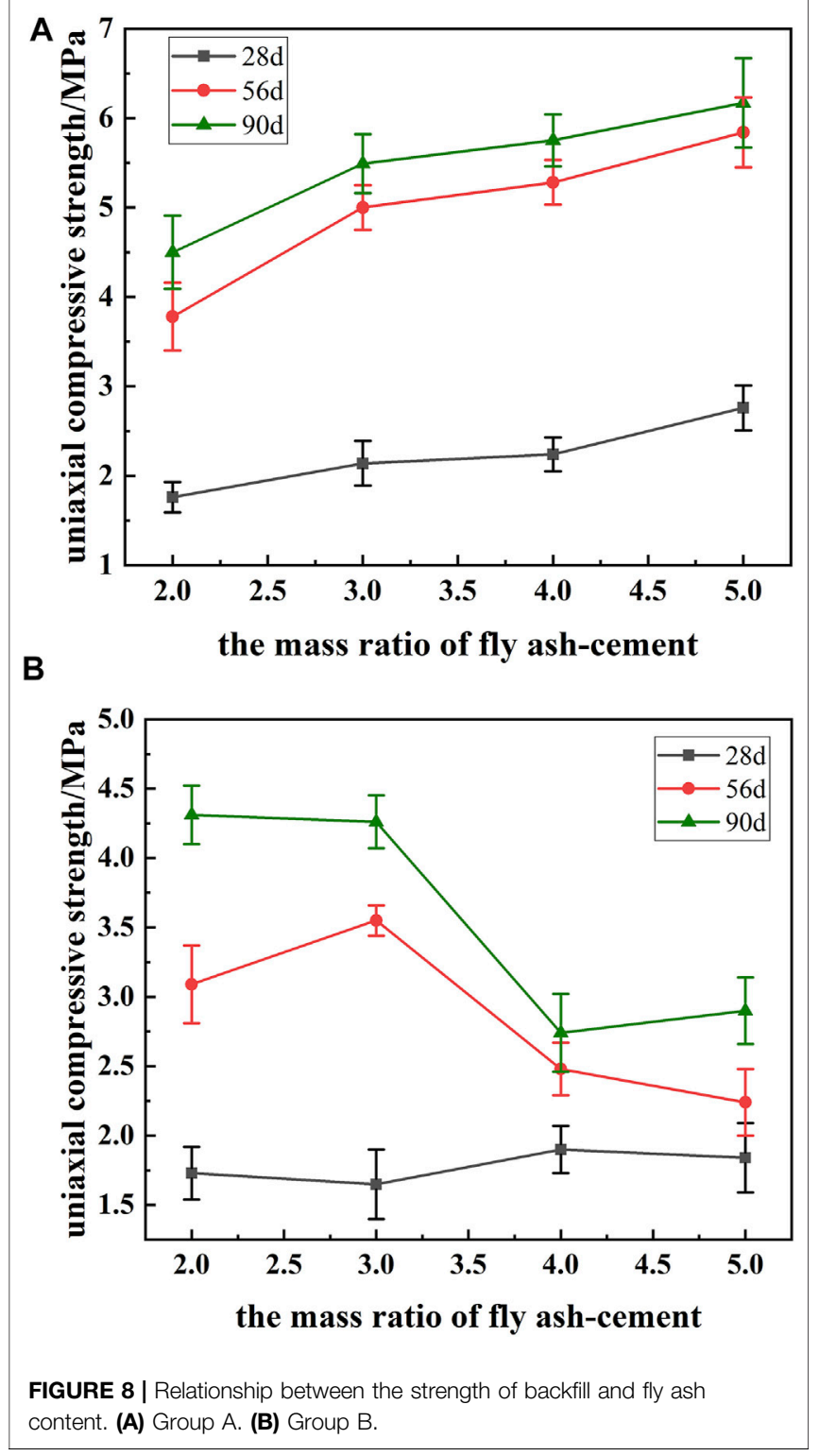

$56 \mathrm{~d}$, after which the growth trend slowed down. As shown in Figure 8B, when the filling aggregate was waste rock and tailings with the ratio of 3:1, after the fly ash-cement mass ratio exceeded 3 (the fly ash-tailings mass ratio was about 3:2 at this time), the strength of the backfill suddenly decreased, and fly ash had a great negative effect on the strength at this time, which is different from the study of Dong et al., 2018. Generally, the increase of fly ash content promotes the strength of backfill in the middle and late stages, and the main reason for fly ash inhibiting the strength of backfill in this experiment is as follows: as the tailing particles were fine, the continuous increase of fly ash content led to more fine particles in the backfill, which hindered the hydration of cementitious materials and affected the growth of the backfill strength. Therefore, fly ash has a two-way effect on the late strength of the backfill under the condition of tailings. It is necessary to determine the appropriate filling ratio of tailings and fly ash.

\section{Study on Optimization of Filling Ratio with Fly Ash}

1) From the results of group $A$, it can be seen that under the condition that the filling aggregate is all waste rock, the strength of the backfill shows an increasing trend with the increase of fly ash content. However, when the amount of filling aggregate is too much, the bonding quality of the interface between slurry and aggregate will be reduced, weakening the integrity of the backfill. Therefore, the group $\mathrm{C}$ experiment was conducted to determine the appropriate ratio of filling aggregate to fly ash: the filling slurry concentration was $74 \%$, the cement content was $6.5 \%$, the filling aggregate was all waste rock, and the mass ratios of waste rock-fly ash were 1:1, 2:1, 3:1, and 4:1, respectively. In addition, due to the poor activity of the fly ash, $3 \%$ content $\mathrm{CaO}$ was added to the slurry

As shown in Figure 9, the $28 \mathrm{~d}$ uniaxial compressive strength of the backfill gradually decreased with the increase of waste rock 


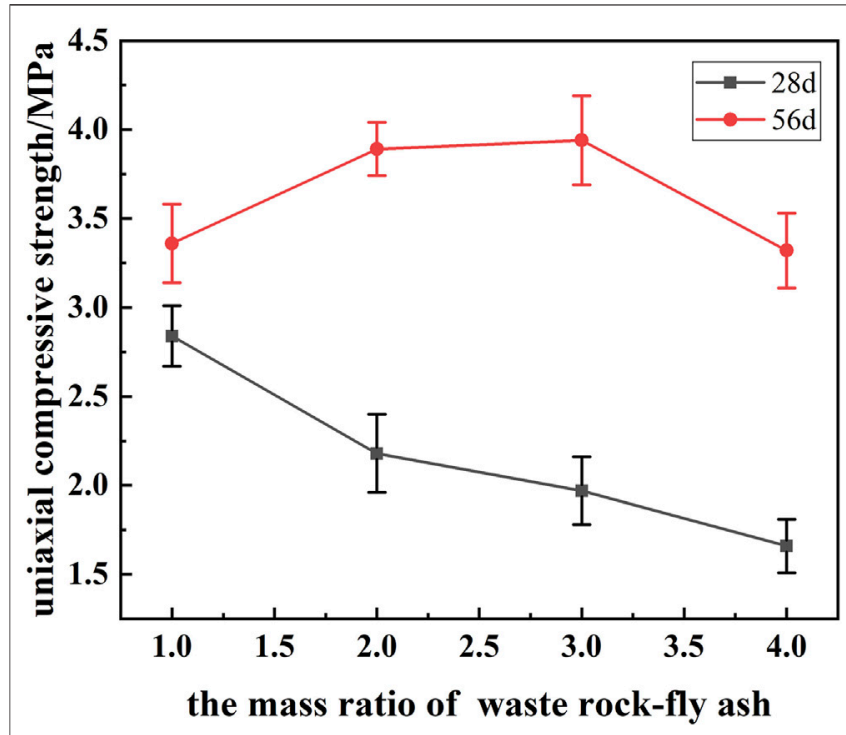

FIGURE 9 | The relationship between backfill strength and mass ratio of waste rock to fly ash (group C).

content, while the $56 \mathrm{~d}$ uniaxial compressive strength showed a trend of increasing and then decreasing. As fly ash mainly affected the strength of the backfill in the middle and late stages, the fly ash was not heavily hydrated at $28 \mathrm{~d}$. The waste rock was not completely wrapped by the gel and the integrity was poor; therefore, the strength at $28 \mathrm{~d}$ decreased with the increase of waste rock; while at $56 \mathrm{~d}$, the fly ash was hydrated to produce a large amount of gel and wrapped waste rock, which showed that the strength of the backfill was higher than that at $28 \mathrm{~d}$, and increased first with the increase of waste rock content. When the waste rock-fly ash mass ratio exceeded 2:1, too much waste rock was not wrapped. The $56 \mathrm{~d}$ strength of the backfill started to decrease, which was the optimal value of the waste rock to fly ash, that is, the early strength of the backfill met the demand and had no inhibitory effect on the middle and late strength.

2) Group $D$ experiment was carried out based on the waste rockfly ash mass ratio of 2:1, and tailings were added to the filling aggregate to determine the optimum tailings content. Group $\mathrm{D}$ experiment scheme: the cement content was $6.5 \%$, the mass ratio of waste rock-fly ash was $2: 1$, the mass ratios of waste rock-tailings were $1: 1,2: 1,3: 1$, and 4:1, respectively, and $\mathrm{CaO}$ content was $3 \%$

As can be seen from Figure 10, with the increase of waste rock to tailings mass ratio, i.e., with the decrease of tailings content, the $28 \mathrm{~d}$ uniaxial compressive strength of the backfill increased linearly. The $56 \mathrm{~d}$ uniaxial compressive strength showed a trend of first increase and then decrease. The minimum strength of the backfill was $1.16 \mathrm{MPa}$ when the mass ratio of waste rock-tailings was $1: 1$, which was better than that of the backfill without fly ash; the $56 \mathrm{~d}$ uniaxial compressive strength reached the maximum when the waste rock-tailings mass ratio

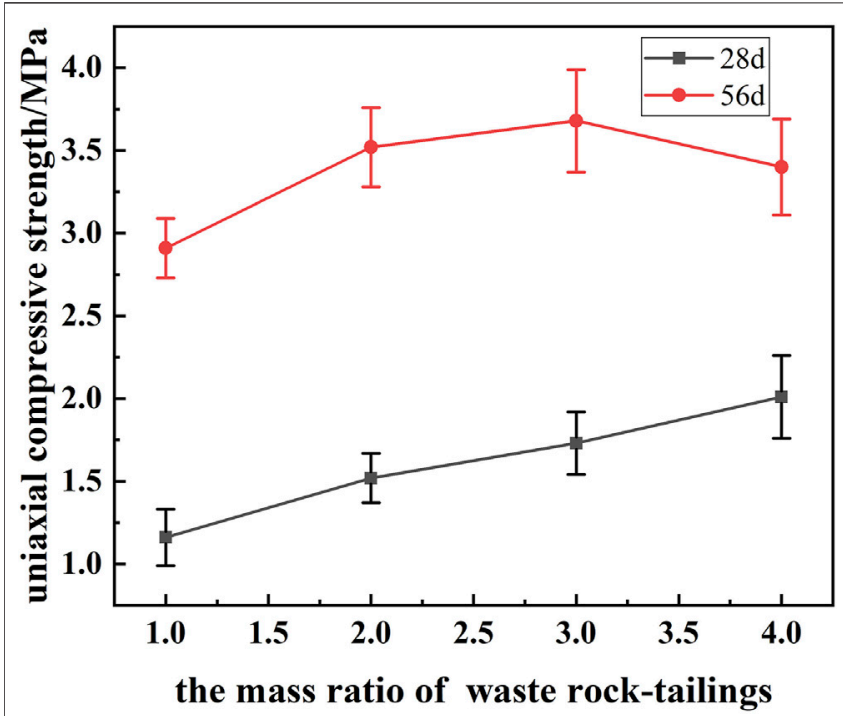

FIGURE 10| The relationship between backfill strength and waste rock to tailings ratio (group D).

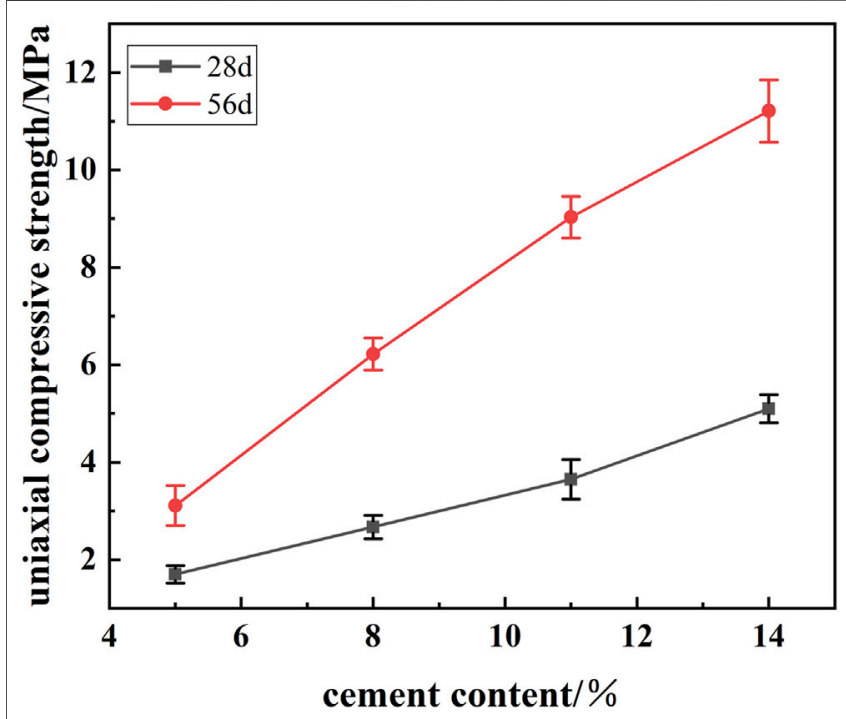

FIGURE 11 | The relationship between the strength of backfill and cement content (group E).

was 3:1. At this time, the number of tailings had no inhibiting effect on both $28 \mathrm{~d}$ and $56 \mathrm{~d}$ uniaxial compressive strength.

3) Based on the results of group $C$ and group $D$, the optimal mass ratio of waste rock-tailings-fly ash was determined to be 6:2:3. On this basis, group E experiments were conducted to determine the optimal cement content to meet the filling demand of the mine: the mass ratio of waste rock-tailings-fly ash was $6: 2: 3, \mathrm{CaO}$ content was $3 \%$, and the cement content was $5,8,11$, and $14 \%$, respectively. 
From Figure 11, it can be seen that the uniaxial compressive strength of the backfill at 28 and $56 \mathrm{~d}$ increases linearly with the increase of cement content, and the fitting equations are as follows:

$$
\begin{aligned}
& 28 \mathrm{~d}: \cdot y=0.373 x-0.26\left(R^{2}=0.989\right), \\
& 56 d: \cdot y=0.904 x-1.19\left(R^{2}=0.994\right)
\end{aligned}
$$

where $y$ is the uniaxial compressive strength of the backfill, $\mathrm{MPa}$; $\mathrm{x}$ is cement content. The slope of the $56 \mathrm{~d}$ fitting equation was significantly greater than that of $28 \mathrm{~d}$, i.e., its strength development was significantly higher than that of $28 \mathrm{~d}$. The increase of cement content had a more obvious effect on the $56 \mathrm{~d}$ strength of the backfill. This was mainly since $28-56 \mathrm{~d}$ was the main hydration stage of fly ash, and the increase of cement content led to the increase of generated $\mathrm{OH}^{-}$, which promoted the hydration of a large amount of fly ash during 28-56 d.

4) When the filling slurry concentration was $74 \%$, the mass ratio of waste rock-tailings-fly ash was $6: 2: 3, \mathrm{CaO}$ content was $3 \%$, and cement content was 5\%; the uniaxial compressive strength of the backfill at 28 and $56 \mathrm{~d}$ was 1.70 and $3.11 \mathrm{Mpa}$, respectively, which met the demand of filling of the mine. Based on the market price of building materials at the mine site, the filling cost was calculated as follows: the price of 32.5 ordinary Portland cement bought from local cement plant was RMB 340 per ton; the waste rock was produced from underground mining, and the transportation and crushing cost was RMB 20 per ton; all tailings were purchased from other mines at a cost of RMB 18 per ton; fly ash was taken from nearby thermal power generation at a price of RMB 70 per ton; $\mathrm{CaO}$ was purchased from local enterprises at a price of $\mathrm{RMB}$ 240 per ton. After calculation, with the filling slurry concentration of $74 \%$, the mass ratio of waste rock-tailingsfly ash of 6:2:3, $\mathrm{CaO}$ content of $3 \%$, and cement content of $5 \%$, the cost of filling slurry was RMB 80.32 per cubic meter. Compared with the current filling ratio under the condition of $74 \%$ concentration of filling slurry, $10 \%$ cement content, and 3:1 mass ratio of waste rock-tailings, it can save RMB 0.56 per cubic meter. In addition, the strength of the backfill can be increased by about $1 \mathrm{MPa}$ at $28 \mathrm{~d}$ and $2 \mathrm{MPa}$ at $56 \mathrm{~d}$. It not only makes a large amount of use of fly ash and reduces the cost of filling but also improves the strength of the backfill significantly, which improves the safety factor and economic benefits of mining.

\section{Analysis of Microstructure and Strength Variation Characteristics of the Backfill}

To analyze the reasons for the strength variation of the backfill, the backfill of the stope, group A3, and group B3 were selected, respectively. Their images were magnified to 2000 times to observe the microstructure by scanning electron microscope. The images of the backfill are shown in Figure 12.

The backfill is a porous structure composed of cementitious material hydrated colloid, $\mathrm{Ca}(\mathrm{OH})_{2}$ crystals, solid particles, and pores, etc. The relationship between its strength and porosity is as follows:

$$
S=S_{0} \exp (-b p)
$$

where $S$ is the ideal state strength of the backfill, $\mathrm{MPa} ; S_{0}$ is the strength of the backfill when the porosity is $0, \mathrm{MPa} ; b$ is a constant related to the cementitious material and maintenance age; $p$ is the internal porosity of the backfill. It can be seen that the strength decreases exponentially as the porosity of the backfill increases, which can be analyzed visually by the structural characteristics of the backfill pores (Cao and Song, 2018; Nakata et al., 2018; Wang and Qiao, 2019). The reaction process of cement and fly ash hydration in the backfill: $\mathrm{C}_{3} \mathrm{~S}, \mathrm{C}_{2} \mathrm{~S}, \mathrm{C}_{3} \mathrm{~A}$, and $\mathrm{C}_{4} \mathrm{AF}$ in cement react with water to generate $\mathrm{Ca}(\mathrm{OH})_{2}$ and $\mathrm{C}-\mathrm{S}-\mathrm{H}$, calcium aluminate, and other gel materials, in which $\mathrm{Ca}(\mathrm{OH})_{2}$ is the intermediate product to promote the mutual reaction of ions in the solution and then reacts with a large amount of $\mathrm{SiO}_{2}$ and $\mathrm{Al}_{2} \mathrm{O}_{3}$ in fly ash to promote the generation of gel materials. The gel material can bind to the aggregate and fill the pore structure after hardening and is the key component affecting the strength of the backfill (Yu et al., 2018).

From Figure 12A, the $28 \mathrm{~d}$ scanning electron microscope of the backfill can be seen that the cement was hydrated to generate part of the flocculent C-S-H gel, accompanied by a small amount of fibrous AFt and plate-like $\mathrm{Ca}(\mathrm{OH})_{2}$ crystals. There were still some inert particles around the gel that have not been wrapped. The overall structure was relatively loose, with a more developed pore structure (Zhang et al., 2021). The strength of the backfill was low at $0.67 \mathrm{MPa}$, which did not meet the demand of the mine; Figure 12B shows the structure of the backfill at $28 \mathrm{~d}$ under the condition of adding fly ash and waste rock. The hydration of cement and fly ash was obvious, generating a large number of flocculent C-S-H gel, and the hydration products were staggered and well wrapped around the aggregate. Compared with Figure $12 \mathrm{~A}$, the structural integrity and connectivity were enhanced. The pores were filled with C-S-H gels. The strength was well developed, reaching 2.24 MPa. Figure 12C shows the structure of the $28 \mathrm{~d}$ backfill under the condition of adding fly ash, waste rock, and tailings. Due to the increase of fine particles in the slurry caused by the addition of fly ash and tailings, and the poor hydration condition of fly ash, the amount of C-S-H gel was reduced compared with Figure 12B. A large number of fine particles of tailings were not connected and the distribution was more dispersed, which led to the increase in the porosity of the backfill and the inability to form a dense structure (Liu et al., 2018; Fu et al., 2020). The macroscopic performance of the backfill strength is reduced to $1.90 \mathrm{MPa}$. Comparing Figure 9D and Figure 9A, it can be seen that during 28-56 d, the flocculent gel further developed and closely connects with the aggregate. Besides, the tightness of the backfill increased significantly and the porosity decreased, i.e., a large amount of hydration reaction of fly ash occurs during 28-56 d.

Based on the results of scanning electron microscope analysis and the hydration characteristics of cement and fly ash, the strength variation process of the backfill containing fly ash can be divided into three stages: cement hydration period, fly ash 

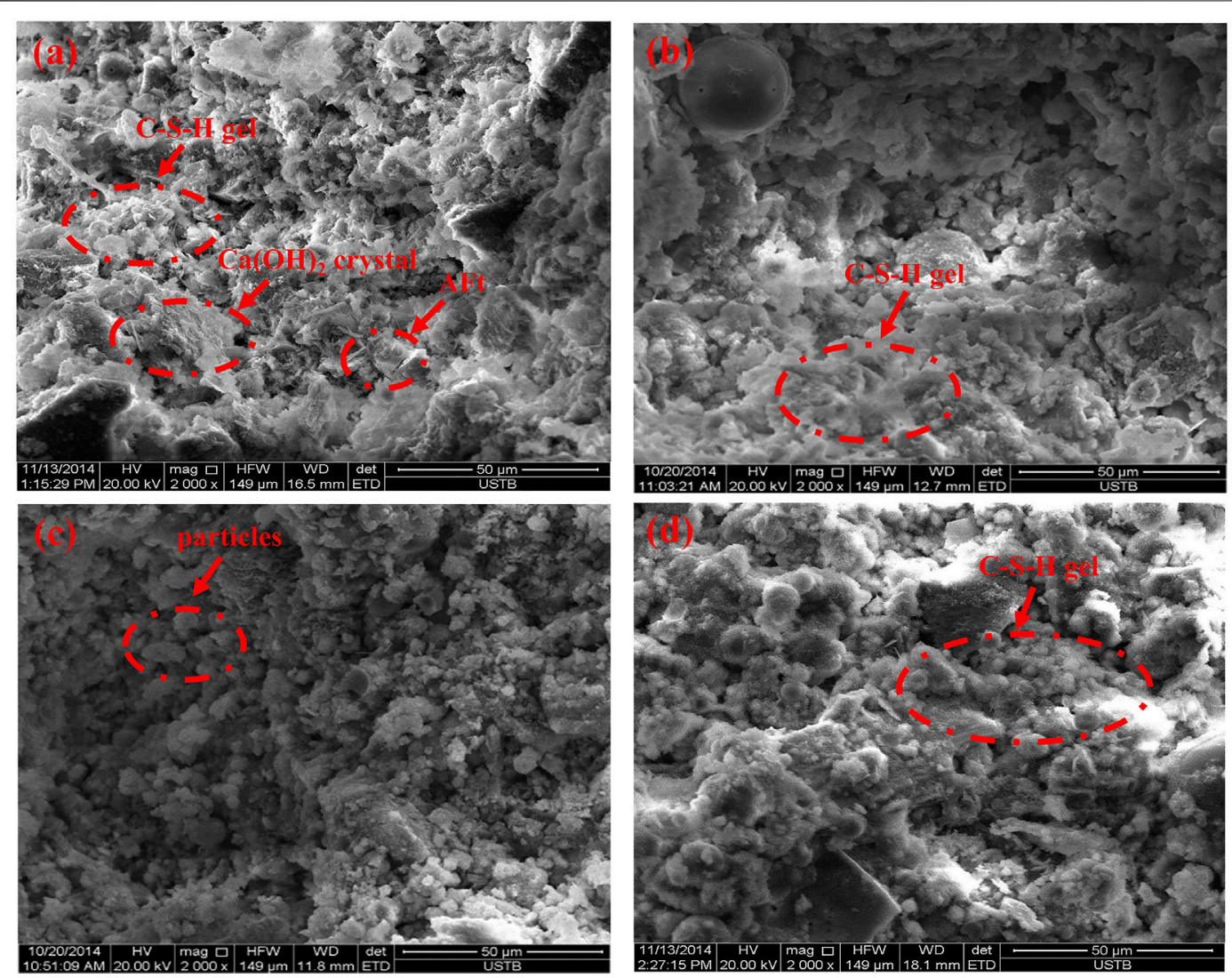

FIGURE 12 | Scanning electron microscope comparison of the backfill. (A) $28 \mathrm{~d}$ backfill of stope. (B) $28 \mathrm{~d}$ backfill of group A3. (C) $28 \mathrm{~d}$ backfill of group B3. (D) $56 \mathrm{~d}$ backfill of group $\mathrm{A} 3$.

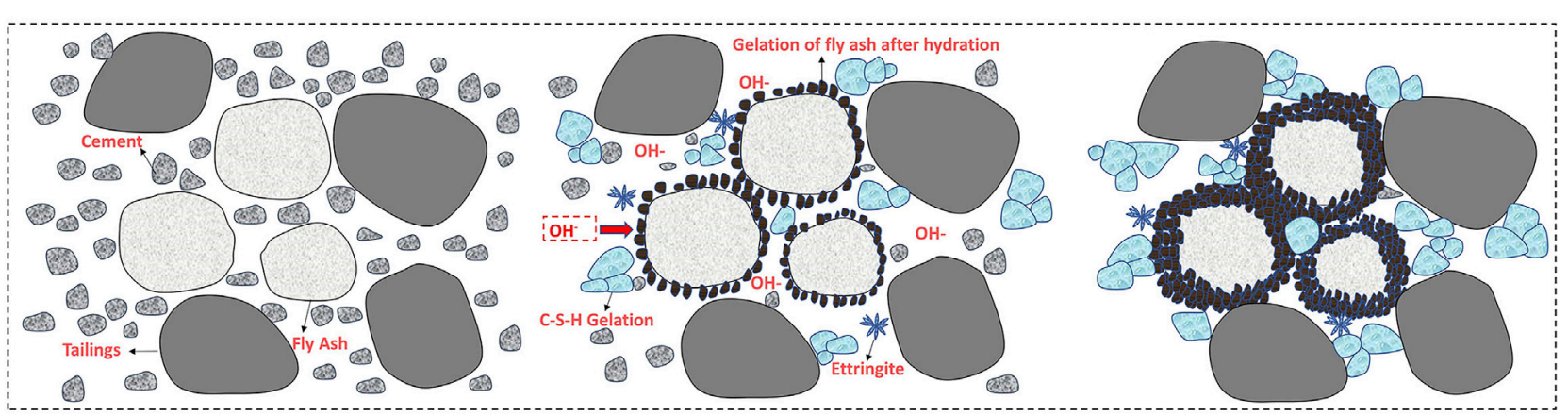

FIGURE 13 | The strength variation process of backfill.

infiltration period, and slurry hardening period, as shown in Figure 13.

During the hydration period of cement, $\mathrm{C}_{3} \mathrm{~S}, \mathrm{C}_{2} \mathrm{~S}, \mathrm{C}_{3} \mathrm{~A}$, and $\mathrm{C}_{4} \mathrm{AF}$ in cement were hydrated to generate $\mathrm{Ca}(\mathrm{OH})_{2}, \mathrm{C}-\mathrm{S}-\mathrm{H}$, and other gel materials. The slurry is in a strong alkali state, and the surface of fly ash was wrapped by gel particles after hydration, which led to slow $\mathrm{OH}^{-}$infiltration, thus reducing its hydration rate and less participation in the early stage of hydration. During the fly ash infiltration period, although the gels were gathered on the surface of fly ash particles, their structure was not stable and was continuously destroyed and reorganized under the osmotic pressure of the slurry solution to promote $\mathrm{OH}^{-}$infiltration (Zhang et al., 2020; He et al., 2021). In addition, the pores between the cementitious particles also provided channels for $\mathrm{OH}^{-}$immersion. The $\mathrm{OH}^{-}$reacted with a large amount of $\mathrm{SiO}_{2}$ and $\mathrm{Al}_{2} \mathrm{O}_{3}$ in fly ash to accelerate the hydration of fly ash in the middle and late stages, which continuously generated C-S-H and calcium aluminate gels, and it was the main stage of hydration 
reaction occurring in fly ash. However, when tailings were added to the slurry, the hydration conditions of fly ash deteriorated due to its finer particles and larger specific surface, which could be uniformly distributed around the fly ash and reduced the contact area between fly ash and $\mathrm{Ca}(\mathrm{OH})_{2}$ (Lee and Kim, 2017; Liu et al., 2018). The fly ash itself had no strength, thus presenting the results of group B: when the fly ash-cement mass ratio exceeded 3, the late strength of the backfill decreased instead. During the hardening period of the slurry, the gel particles generated by the hydration reaction of cement and fly ash combined and continuously formed a structurally stable gel and wrapped coarse and fine aggregates to form a dense structure with reduced porosity, which macroscopically showed an increase in the strength of the filled body. Therefore, to play the role of fly ash in the backfill, firstly, it was necessary to determine the appropriate cementitious material ratio to generate the right amount of $\mathrm{OH}^{-}$during the hydration period of cement to maximize the activation of fly ash and increase its hydration; secondly, the gel structure produced by hydration needed to be in excellent ratio with the aggregate in the stage of slurry hardening period, with good connection performance to reduce the porosity and ensure the quality of the backfill.

\section{CONCLUSION}

In this paper, the effect of fly ash on the backfill strength was analyzed based on the experiments of the filling ratio containing fly ash, and the variation process of backfill strength was analyzed. The specific conclusions are as follows:

1) Fly ash had a promoting effect on the strength of the backfill, and the strength development was mainly concentrated on 28-56 d; When the filling material contains tailings, adding too much fly ash will lead to a large number of fine particles in the backfill, hindering the hydration of cementitious material and affecting the development of backfill strength.

\section{REFERENCES}

Ardahanli, M., Oltulu, M., and Alameri, I. (2021). The Effect of Preheating on the Properties of the Fly Ash Self-Compacting Concrete. Black Sea J. Eng. Sci. 4, 81-88. doi:10.34248/bsengineering.858520

Behera, S. K., Mishra, D. P., Ghosh, C. N., Prashant, Mandal, P. K., Singh, K. M. P., et al. (2019). Characterization of lead-zinc Mill Tailings, Fly Ash and Their Mixtures for Paste Backfilling in Underground Metalliferous Mines. Environ. Earth Sci. 78, 394. doi:10.1007/s12665-019-8395-9

Cao, S., and Song, W. (2018). Medium-Term Strength and Electromagnetic Radiation Characteristics of Cemented Tailings Backfill under Uniaxial Compression. Geotech. Geol. Eng. 36, 3979-3986. doi:10.1007/s10706-018-0542-7

Capasso, I., Lirer, S., Flora, A., Ferone, C., Cioffi, R., Caputo, D., et al. (2019). Reuse of Mining Waste as Aggregates in Fly Ash-Based Geopolymers. J. Clean. Prod. 220, 65-73. doi:10.1016/j.jclepro.2019.02.164

Chen, Q.-s., Sun, S.-y., Liu, Y.-k., Qi, C.-c., Zhou, H.-b., and Zhang, Q.-1. (2021). Immobilization and Leaching Characteristics of Fluoride from Phosphogypsum-Based Cemented Paste Backfill. Int. J. Miner. Metall. Mater. 28, 1440, 1452. doi:10.1007/s12613-021-2274-6
2) When the filling slurry concentration was $74 \%$, the cement content was $5 \%$, the mass ratio of waste rock-tailings-fly ash was $6: 2: 3$, and the $\mathrm{CaO}$ content was $3 \%$, the strength of the backfill was significantly higher than that of the current backfill of the mine, and the filling cost could be saved by RMB 0.56 per cubic meter.

3) The pore structure of the backfill determined its strength characteristics. To play the role of fly ash in the backfill, it is first necessary to determine the appropriate ratio of cementitious materials to generate the $\mathrm{OH}^{-}$during the cement hydration period and activate the fly ash; secondly, the gel structure generated by hydration needs to be well proportioned with the aggregate during the slurry hardening period to reduce the porosity and ensure the quality of the backfill.

\section{DATA AVAILABILITY STATEMENT}

The original contributions presented in the study are included in the article/Supplementary Material; further inquiries can be directed to the corresponding authors.

\section{AUTHOR CONTRIBUTIONS}

BC: conceptualization, investigation, and writing-review and editing. CD: supervision. XC: writing-original draft. LZ: methodology and data curation.

\section{FUNDING}

This study was supported by the Funds of National Key Research and Development Program of China (2018YFC0604605) and Fundamental Research Fund for the Central Universities (FRF-TP-19-039A1).

Chen, Y.-g., Guan, L.-l., Zhu, S.-y., and Chen, W.-j. (2021). Foamed concrete Containing Fly Ash: Properties and Application to Backfilling. Construction Building Mater. 273, 121685. doi:10.1016/j.conbuildmat.2020.121685

Cui, B., Liu, Y., Li, H., Guo, H., and Lu, Yao. (2018). Experimental Study of the Chemical Excitation on Gelation of Cement and Fly Ash Filling Paste. Min. Res. Dev. 38, 127-131. doi:10.13827/j.cnki.kyyk.2018.03.028

Dai, X., Ren, Q., Aydın, S., Yardımcı, M. Y., Lesage, K., and De Schutter, G. (2021). Enhancing Thixotropy and Structural Build-Up of Alkali-Activated Slag/fly Ash Pastes with Nano clay. Mater. Struct. 54, 163. doi:10.1617/s11527-02101760-4

Dong, Y., Yang, Z., Gao, Q., and Yang, X. (2018). Effect of Fly Ash Content on Properties of Backfilling Materials Prepared with Iron Tailings. J. Guangxi Univ. 43, 219-225. doi:10.13624/j.cnki.issn.1001-7445.2018.0219

Fan, W.-D., Liu, B., Luo, X., Yang, J., Guo, B., and Zhang, S.-G. (2019). Production of Glass-Ceramics Using Municipal Solid Waste Incineration Fly Ash. Rare Met. 38, 245-251. doi:10.1007/s12598-017-0976-8

Fang, G., Ho, W. K., Tu, W., and Zhang, M. (2018). Workability and Mechanical Properties of Alkali-Activated Fly Ash-Slag concrete Cured at Ambient Temperature. Construction Building Mater. 172, 476-487. doi:10.1016/ j.conbuildmat.2018.04.008 
Fangfang, L., Xiyang, F., and Li, C. (2021). Effect of Different Activators on Rheological and Strength Properties of Fly Ash-Based Filling Cementitious Materials. Adv. Civil Eng. 2021, 1-9. doi:10.1155/2021/5538695

Fu, B., Cheng, Z., and Han, J. (2018). Experimental Study on Impermeability of Alkali Activated Fly Ash-Slag Concrete. Bull. Chin. Ceram. Soc. 37, 2255-2259. doi:10.16552/j.cnki.issn1001-1625.2018.07.031

Fu, J., Wang, J., and Song, W. (2020). Damage Constitutive Model and Strength Criterion of Cemented Paste Backfill Based on Layered Effect Considerations. J. Mater. Res. Tech. 9, 6073-6084. doi:10.1016/j.jmrt.2020.04.011

He, J., Long, G., Ma, K., Xie, Y., and Cheng, Z. (2021). Improvement of the Hydration of a Fly Ash-Cement System by the Synergic Action of Triethanolamine and C-S-H Seeding. ACS Sust. Chem. Eng. 9, 2804-2815. doi:10.1021/acssuschemeng.0c08618

Hu, J., Zhao, F., Ren, Q., Kuang, Y., Zhou, T., and Luo, Z. (2019). Microscopic Characterization and Strength Characteristics of Cemented Backfill under Different Humidity Curing Conditions. R. Soc. Open Sci. 6, 191227. doi:10.1098/rsos.191227

Huang, S., Yan, E., Fang, K., and Li, X. (2021). Effects of Binder Type and Dosage on the Mode I Fracture Toughness of Cemented Paste Backfill-Related Structures. Construction Building Mater. 270, 121854. doi:10.1016/j.conbuildmat.2020.121854

Lee, S.-H., and Kim, G.-S. (2017). Self-cementitious Hydration of Circulating Fluidized Bed Combustion Fly Ash. J. Korean Ceram. Soc. 54, 128-136. doi:10.4191/kcers.2017.54.2.07

Li, G., Sun, Y., and Qi, C. (2021). Machine Learning-Based Constitutive Models for Cement-Grouted Coal Specimens under Shearing. Int. J. Mining Sci. Tech. doi:10.1016/j.ijmst.2021.08.005

Liang, Y., Kong, H., Wang, C., Sun, Q., and Wang, D. (2019). Study on the Strength of Fly Ash Paste Filling Replacing Strip Pillar. Min. Res. Dev. 39, 84-87. doi:10.13827/j.cnki.kyyk.2019.07.018

Liu, S., Li, Z., Li, Y., and Cao, W. (2018). Strength Properties of Bayer Red Mud Stabilized by Lime-Fly Ash Using Orthogonal Experiments. Construction Building Mater. 166, 554-563. doi:10.1016/j.conbuildmat.2018.01.186

Liu, X., Zhao, X., Yin, H., Chen, J., and Zhang, N. (2018). Intermediate-calcium Based Cementitious Materials Prepared by MSWI Fly Ash and Other Solid Wastes: Hydration Characteristics and Heavy Metals Solidification Behavior. J. Hazard. Mater. 349, 262-271. doi:10.1016/j.jhazmat.2017.12.072

M. Azmee, N., and Shafiq, N. (2019). Investigating the Impacts of Ultra-Fine Calcium Carbonate in High-Volume Fly Ash Concrete for Structural Rehabilitation for Sustainable Development. Sustainability 11, 4671-4716. doi:10.3390/su11174671

Nakata, Y., Saito, T., Kajita, H., Otsuka, S., and Haruyama, N. (2018). Influence on Properties of High-Strength concrete by the Change of Sand-Total Aggregate Ratio in Identical Water-Cement Ratio. Nihon Kenchiku Gakkai Kozokei Ronbunshu 83, 751-761. doi:10.3130/aijs.83.751

Nath, P., and Sarker, P. K. (2015). Use of OPC to Improve Setting and Early Strength Properties of Low Calcium Fly Ash Geopolymer concrete Cured at Room Temperature. Cement and Concrete Composites 55, 205-214. doi:10.1016/j.cemconcomp.2014.08.008

Qi, C., and Fourie, A. (2019). Cemented Paste Backfill for mineral Tailings Management: Review and Future Perspectives. Minerals Eng. 144, 106025. doi:10.1016/j.mineng.2019.106025

Wang, C., Liu, Y., Hu, H., Li, Y., and Lu, Y. (2019). Study on Filling Material Ratio and Filling Effect: Taking Coarse Fly Ash and Coal Gangue as the Main Filling Component. Adv. Civil Eng. 2019, 1-11. doi:10.1155/2019/2898019

Wang, H., and Qiao, L. (2019). Coupled Effect of Cement-To-Tailings Ratio and Solid Content on the Early Age Strength of Cemented Coarse Tailings Backfill. Geotech Geol. Eng. 37, 2425-2435. doi:10.1007/s10706-018-00766-0
Wang, X. (2020). Experimental Study on the Performance of Goaf Filling Materials with High Content of Fly Ash. IOP Conf. Ser. Earth Environ. Sci. 569, 012014. doi:10.1088/1755-1315/569/1/012014

Xiao, B., Wen, Z., Wu, F., Li, L., Yang, Z., and Gao, Q. (2019). A Simple L-Shape Pipe Flow Test for Practical Rheological Properties of Backfill Slurry: A Case Study. Powder Tech. 356, 1008-1015. doi:10.1016/j.powtec.2019.09.012

Xie, S., Sun, Y., Wang, E., Chen, D., Wu, X., and Qi, P. (2020). Experimental and Mechanistic Research on Modifying the Mechanic Properties of the High Water Backfill Material by Electrochemical Treatment. Sci. Rep. 10, 17027. doi:10.1038/s41598-020-74115-8

Yang, J. (2020). Rheological Study on Cemented Coal Gangue Fly-Ash Backfill Slurry Associated with Fly Ash Impacts. Kem 831, 100-104. doi:10.4028/ www.scientific.net $/ \mathrm{kem} .831 .100$

Yang, X., Li, L., and Gao, Q. (2019). Study on Test and Ratio Optimization of Waste Rock-Fly Ash Aggregate Filling Slurry. IOP Conf. Ser. Earth Environ. Sci. 330, 042032. doi:10.1088/1755-1315/330/4/042032

Yin, B., Kang, T., Kang, J., Chen, Y., Wu, L., and Du, M. (2018). Investigation of the Hydration Kinetics and Microstructure Formation Mechanism of Fresh Fly Ash Cemented Filling Materials Based on Hydration Heat and Volume Resistivity Characteristics. Appl. Clay Sci. 166, 146-158. doi:10.1016/ j.clay.2018.09.019

Yu, J., Li, G., and Leung, C. K. Y. (2018). Hydration and Physical Characteristics of Ultrahigh-Volume Fly Ash-Cement Systems with Low Water/binder Ratio. Construction Building Mater. 161, 509-518. doi:10.1016/j.conbuildmat.2017.11.104

Zafar, I., and Alqahtani, F. K. (2021). Effectiveness of Extended Curing for Fly Ash concrete against Corrosion Propagation under Severe Chloride Exposure. Struct. Concrete, 1-16. doi:10.1002/suco.202000614

Zhang, C., Fu, J., Song, W., Du, C., and Fu, H. (2021). High-volume Ultrafine Fly Ash-Cement Slurry Mechanical Properties and Strength Development Model Establishment. Construction Building Mater. 277, 122350. doi:10.1016/ j.conbuildmat.2021.122350

Zhang, W., Wu, F., and Zhang, Y. (2020). Early Hydration and Setting Process of Fly Ash-Blended Cement Paste under Different Curing Temperatures. J. Wuhan Univ. Technol. 35, 87-96. doi:10.1007/s11595-020-2292-7

Conflict of Interest: Authors XC and LZ were employed by the company Jiaojia Gold Mine, Shandong Gold Mining (Laizhou) Co., Ltd.

The remaining authors declare that the research was conducted in the absence of any commercial or financial relationships that could be construed as a potential conflict of interest.

Publisher's Note: All claims expressed in this article are solely those of the authors and do not necessarily represent those of their affiliated organizations, or those of the publisher, the editors, and the reviewers. Any product that may be evaluated in this article, or claim that may be made by its manufacturer, is not guaranteed or endorsed by the publisher.

Copyright $\odot 2021$ Chang, Du, Chu and Zhang. This is an open-access article distributed under the terms of the Creative Commons Attribution License (CC BY). The use, distribution or reproduction in other forums is permitted, provided the original author(s) and the copyright owner(s) are credited and that the original publication in this journal is cited, in accordance with accepted academic practice. No use, distribution or reproduction is permitted which does not comply with these terms. 